\title{
Intelligence Improvement and Intellect Enrichment by Seven Effective Thinking Patterns (SETP) Tool
}

\author{
Dr. Arvinder Singh ${ }^{1 *}$
}

\section{ABSTRACT}

Intelligence and intellect are the most desirable traits to be improved and various scientists and psychologists are always striving to enrich these. Various methods have been proposed and tested. In most modern researches by the Seven Effective Thinking Patterns (SETP) tool designed and developed by Dr. Arvinder Singh is tested for intelligence enhancement. Guilford Model of Intelligence was tested for intelligence on evaluation and divergent production. The sample comprises of 80 adults randomly selected from colleges, entrepreneur and corporate employees. . The selected parameters for evaluation were i) Number of Alternatives ii) Relevant Alternatives iii) Root Cause Analysis iv) Approach to Data Collection. Pre and Post training scores were evaluated on a scale of 1 to 10 .

The number of alternatives during pre-training situation was $4.25 \pm 1.036$ while for Post-training situation it was $7.46 \pm 1.212$ with increase of $75.5 \%$. The score on relevant alternatives during pre-training situation was $2.56 \pm 1.133$ while for Post-training situation it was $6.81 \pm 1.212$. with percentage increase of $166 \%$. The score on root cause analysis during pre-training situation was $4.55 \pm 1.013$ while for Post-training situation it was $7.98 \pm 0.836$ and percentage increase of $75.4 \%$. The approach to data collection during pre-training situation was $4.64 \pm 0.988$ while for Posttraining situation it was $8.35 \pm 0.969$ with increment of $79.9 \%$. All above parameters reflected p value of less than 0.01 which is highly significant. It can be confidently concluded with above data and research that SETP tool is quite effective and in improving intelligence of participant on Guilford Model of Intelligence.

Keywords: Intelligence Enhancement, Root Cause Analysis, Seven Effective Thinking Patterns, SETP, Creativity, Guilford Intelligence Model.

Intelligence and intellect are the most desirable traits and asset for humanity and it is the basis for evolution of human race. Various researchers, psychologists and scientists are trying to decode the intelligence and mechanism of mind to help the humanity. Researchers have clearly shown that intelligence and intellect is a complex function of brain. There are plenty of factors which operate together for anatomy of intelligence. The most accepted model for intelligence is

\footnotetext{
${ }^{1}$ CEO \& CMD, Rahat Hospital, Udaipur

*Corresponding Author

(c) 2015 I A Singh; licensee IJIP. This is an Open Access Research distributed under the terms of the Creative Commons Attribution License (http://creativecommons.org/licenses/by/2.0), which permits unrestricted use, distribution, and reproduction in any Medium, provided the original work is properly cited.
} 
the Guildford structure of intelligence. This model has got 150 parameters of intellect. The model consists of three components: 1 . Contents 2. Products 3. Operations

In this model obviously the contents and products are more or less uncontrollable but operations can be trained by various mechanisms. To review the operations part of Guildford intelligence theory is made up of five components as follows:
I. Evaluation
II. Divergent Production
III. Convergent Production
IV. Memory
V. Cognition

Seven Effective Thinking Patterns (SETP) tool designed, developed and patented by Dr Arvinder Singh has got different components of training different faculties of mind namely problemsolving, decision-making, creativity and memory. It is well accepted that these components can be objectively trained and once these factors are trained automatically intellectual ability of the person increases manifolds. The Seven Effective Thinking Patterns are:
i. Meta-cognitive Thinking Pattern
ii. Objective Thinking Pattern
iii. Constructive Thinking Pattern
iv. Critical Thinking Pattern
v. Creative Thinking Pattern
vi. Emotive Thinking Pattern
vii. Radiant Thinking Pattern

The "SETP" teaches how to use these patterns and customize sequential order of employing the thinking pattern depending on the varying situation.

\section{REVIEW OF LITERATURE}

Lieberman (1965) was of opinion that developing one's divergent thinking skills is thought to enhance creativity. Creativity can be seen as an ability to retrieve and connect disparate concepts stored in long-term memory systems. Lloyd Humphreys (1979) was of opinion that the intellect is resultant of the process of acquiring, storing in memory, retrieving, combining, comparing, and using in new contexts information and conceptual skills. Reuven Feuerstein (1990) expressed that the theory of Structural Cognitive Modifiability describes intelligence as "the unique propensity of human beings to change or modify the structure of their cognitive functioning to adapt to the changing demands of a life situation. Howard Gardner (1993) said that to my mind, a human intellectual competence must entail a set of skills of problem solving - enabling the individual to resolve genuine problems or difficulties that he or she 
encounters and, when appropriate, to create an effective product - and must also entail the potential for finding or creating problems - and thereby laying the groundwork for the acquisition of new knowledge. According to J.P. Guilford (2015), intellect consists of three key parameters: operations, contents and products. Each parameter contains specific elements, which are independent and therefore should be measured individually and considered as autonomous units of human intellect.

\section{MATERIAL AND METHODS}

The sample comprises of 80 adults randomly selected from colleges, entrepreneur and corporate employees. The age of sample ranges between 18 to 45 years and were 51 Males and 29 Females. They were all of different socio-economic status and were having secondary education as minimum qualification. They were evaluated on the basis of analysis of the situation "Factory Workers have given notice for strike". They were asked to write for root cause analysis and approach to data collection in 20 minutes. The second parameter to be judged was number of alternative and relevancy of alternatives for the given situations and the subjects were given 20 minutes to write the ideas. The answer sheets were labelled by unique number. Then subjects were trained by SETP tool. After training program they were asked to generate and relate analysis and ideas on the same topic and the answer sheets were labelled again by unique number.

Two independent evaluators on prescribed parameters evaluated answer sheets and given scores of both were averaged. The evaluators were kept blind about any tool applied and were not told that they are evaluating the same student twice. In short evaluators evaluated 160 copies unaware of SETP tool application. The selected parameters for evaluation were:
I. Number of Alternatives
II. Relevant Alternatives
III. Root Cause Analysis
IV. Approach to Data Collection

The evaluation was done on a scale of 1 to 10 . Results were analyzed by the Paired ' $t$ ' test was used for comparing pre and post training scores. All the calculations were done through Microsoft Excel. 


\section{RESULTS}

Table below showing Comparison of scores of the four factors before and after training by Seven Effective Thinking Patterns (SETP) tool

\begin{tabular}{|c|c|c|c|c|c|c|}
\hline & & Mean & $\mathbf{N}$ & $\begin{array}{l}\text { Std. } \\
\text { Deviation }\end{array}$ & $\begin{array}{l}\text { Percentage } \\
\text { Change }\end{array}$ & P value \\
\hline \multirow[t]{2}{*}{ Number of Alternatives } & Pre-training & 4.25 & 80 & 1.036 & \multirow{2}{*}{$75.5 \%$} & \multirow{2}{*}{$<0.01$} \\
\hline & Post-training & 7.46 & 80 & 1.212 & & \\
\hline \multirow[t]{2}{*}{ Relevant Alternatives } & Pre-training & 2.56 & 80 & 1.133 & \multirow{2}{*}{$166 \%$} & \multirow{2}{*}{$<0.01$} \\
\hline & Post-training & 6.81 & 80 & 1.212 & & \\
\hline \multirow{2}{*}{$\begin{array}{l}\text { Root } \\
\text { Analysis }\end{array}$} & Pre-training & 4.55 & 80 & 1.013 & \multirow{2}{*}{$75.4 \%$} & \multirow{2}{*}{$<0.01$} \\
\hline & Post-training & 7.98 & 80 & 0.836 & & \\
\hline \multirow{2}{*}{$\begin{array}{l}\text { Approach to Data } \\
\text { Collection }\end{array}$} & Pre-training & 4.64 & 80 & 0.988 & \multirow[b]{2}{*}{$79.9 \%$} & \multirow[b]{2}{*}{$<0.01$} \\
\hline & Post-training & 8.35 & 80 & 0.969 & & \\
\hline
\end{tabular}

\section{Chart}

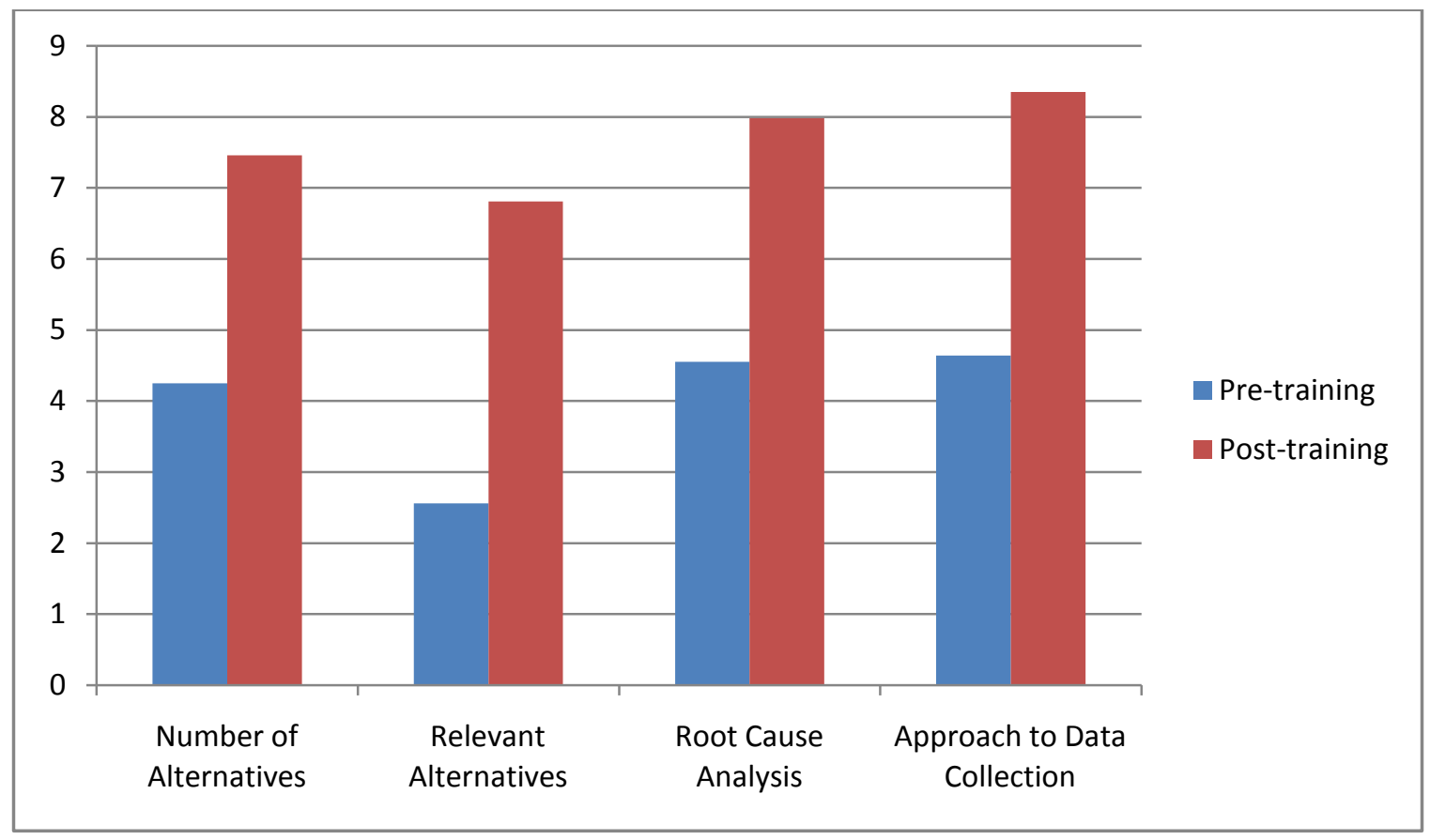

\section{DISCUSSION}

The above table shows the mean and standard score on number of alternatives during pretraining situation was $4.25 \pm 1.036$ while for Post-training situation it was $7.46 \pm 1.212$. which is significant at $\mathrm{P}$ value less than 0.01. Percentage increase from pretraining to post training is 75.5\%. It infers that there is significant difference between Pre and Post-training scores. 
Furthermore the mean scores reflect that there is significantly positive impact of SETP training in increasing number of alternatives.

The above table visualizes the mean and standard score on relevant alternatives during pretraining situation was $2.56 \pm 1.133$ while for Post-training situation it was $6.81 \pm 1.212$. The mean difference was found to be 3.960 and $\mathrm{P}$ value is significant at less than 0.01 levels. Percentage increase from pretraining to post training is $166 \%$. It proves that there is significant difference between pre and Post-training scores. Furthermore the mean scores reveal that there is significantly positive impact of SETP training in generating relevant alternatives.

The above table indicates the mean and standard score on root cause analysis during pre-training situation was $4.55 \pm 1.013$ while for Post-training situation it was $7.98 \pm 0.836$. $\mathrm{P}$ value is significant at less than 0.01 levels. Percentage increase from pretraining to post training is 75.4\%. It results that there is significant difference between Pre and Post-training scores. Furthermore the mean scores supports that there is significantly positive impact of SETP training in improving root cause analysis.

The above table denotes the mean and standard score on approach to data collection during pretraining situation was $4.64 \pm 0.988$ while for Post-training situation it was $8.35 \pm 0.969$. $\mathrm{P}$ value is significant at less than 0.01 levels. Percentage increase from pretraining to post training is 79.9\%. It signifies that there is significant difference between Pre and Post-training scores. Furthermore the mean scores deduce that there is significantly positive impact of SETP training in improving approach to data collection.

\section{CONCLUSION}

Intellect and Intelligence are the most valuable and strategic assets for achieving long-term success not only in financial terms but also all other desirable parameters of life. Various tools have been claimed for enhancement of intelligence. SETP tool is quite promising in the sense that it is having an objective criteria plotted and linked with Guilford structure of intelligence. By the parameters examined in this test obviously the operational part of intelligence namely evaluation and divergent thinking is trained with proper measuring scale. On various parameters listed in this study the improvement shown is more than $70 \%$ and for few students it was more than double. So it can be concluded with confidence that a SETP tool is very effective and promising tool for training of intellect and intelligence enhancement.

\section{REFERENCES}

Carson, Shelley (2010), Your Creative Brain: Seven Steps to Maximize Imagination, Productivity and Innovation in Your Life, Jossey Bass

Feuerstein, R., Feuerstein, S., Falik, L \& Rand, Y. (1979; 2002). Dynamic assessments of cognitive modifiability. ICELP Press, Jerusalem: Israel; Feuerstein, R. (1990). The theory 
of structural modifiability. In B. Presseisen (Ed.), Learning and thinking styles: Classroom interaction. Washington, DC: National Education Associations

Frames of mind: The theory of multiple intelligences. New York: Basic Books. 1993.

Guilford, J.P. \& Hoepfner, R. (1971). The Analysis of Intelligence

Guilford, J.P. (1967). The Nature of Human Intelligence.

Humphreys, L. G. (1979). "The construct of general intelligence". Intelligence 3 (2): 105-120.

Osborn, Alex F. (1953), Applied Imagination: Principles and Procedures of Creative Problem Solving, New York: Charles Scribner's Sons

Singh Arvinder and Choudhary, Ajay K. (2015) SETP Tool for Creativity and Innovation Enhancement (Modified Application for Teenagers), Research Journal of Social Science \& Management-RJSSM, Singapore ISSN 2251-1571

Singh Arvinder and Choudhary, Ajay K. (2015), SETP: A New Powerful Tool for Improving Problem Solving, Decision Making and Creativity in Teenagers, The International Journal of Indian Psychology. ISSN 2348-5396 (e)| ISSN: 2349-3429 (p)

Spearman, C. (1904). "General intelligence” objectively determined and measured. American Journal of Psychology, 15, 201-293.

Structure of Intellect (J.P. Guilford)". www.instructionaldesign.org. Retrieved 2015-10-28

Wechsler, D (1944). The measurement of adult intelligence. Baltimore: Williams \& Wilkins 